Gut, 1986, 27, 1369-1372

\title{
Smoking and mortality from peptic ulcer in the United Kingdom
}

\author{
AMNON SONNENBERG \\ From the Department of Medicine, Division of Gastroenterology, Beth Israel Hospital, Harvard School of \\ Medicine, Boston, MA, USA
}

SUMMARY The present paper compares the temporal changes of cigarette consumption with those of peptic ulcer mortality in the United Kingdom. Cumulative cigarette consumption increased in men born between 1845 and 1915 and remained constant or decreased in all subsequent generations. It increased in women born between 1835 and 1955 . In contrast, both male and female mortality from gastric and duodenal ulcer were highest in those born around 1875-1885. From the lack of coincidence in the trends of peptic ulcer mortality and cumulative cigarette consumption it is concluded that changing smoking habits were not responsible for the birth cohort patterns of the death rates from gastric and duodenal ulcer.

Mortality from gastric and duodenal ulcer in many European countries changed in a manner that can be explained by changes in birth cohort risks. ${ }^{12}$ Generations born at the end of the 19th century manifested a high risk of dying from peptic ulcer and carried it throughout their lives. The death rates of gastric and duodenal ulcer decreased in all subsequent generations. The simultaneous occurrence of a birth cohort pattern in different European countries, ${ }^{2}$ Japan, ${ }^{3}$ and the United States ${ }^{4}$ suggests that worldwide, at the same time, the same environmental factors precipitated the risk of dying from gastric and duodenal ulcer. The present paper examines whether the temporal changes of cigarette consumption could have accounted for the birth cohort pattern of ulcer mortaiity.

\section{Methods}

CONSUMPTION RATES

Estimates of cigarette consumption by men and women for each five year age group in each year during the period 1890-1975 and 1972-1982 were published by the Tobacco Research Council and the British Office of Population Censuses and Surveys. ${ }^{5-7}$ An index of the average deliveries of tar and nicotine per cigarette for the year 1935 and for

Address for correspondence: Amnon Sonnenberg MD, VA Medical Center, Section of Gastroenterology, $5000 \mathrm{~W}^{*}$ ' nal Avenue. Milwaukee, Wisconsin 53295, USA.

Received for publication 21 February 1986.
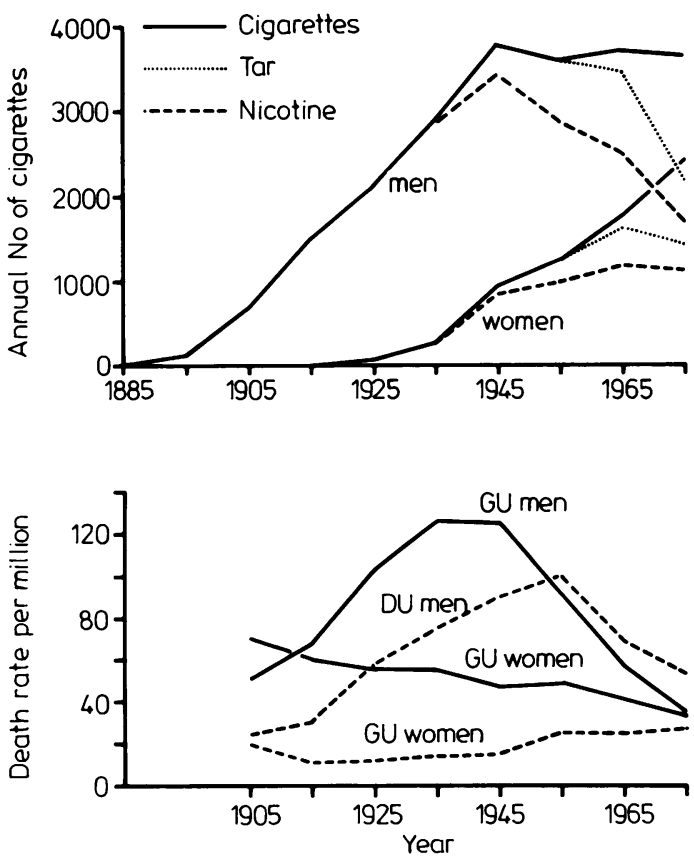

Fig. 1 Cigarette consumption per man and woman resident in the $U K$ (upper part) and $U K$ death rates from gastric and duodenal ulcer (GU and DU, lower part). Each noint represents the annual average of a 10 year period named after its central year. The death rates of 1900-1909 and 1910-1919 were calculated from the figures of Susser and Stein. ${ }^{\prime}$ The rates were adjusted to the age distribution of the UK population in 1970-79. 
each year since 1965 were published by the Tobacco Research Council and by Merzdorf et al. ${ }^{58}$ The delivery in the cigarettes smoked during each year of the period 1936-1964 was estimated by linear interpolation from the values of 1935 and 1965 . By setting the delivery of nicotine in cigarettes from 1935 and previous years as $100 \%$, the cigarette consumption of the subsequent years until 1979 was converted to constant tar and constant nicotine cigarettes. Wald and coworkers studied the tar and nicotine deliveries of cigarettes manufactured in the United Kingdom since $1934 .{ }^{9}$ Their set of figures was also applied to calculate constant tar and constant nicotine cigarettes.

The table of the age- and sex-specific annual numbers of cigarettes consumed during each year of the period 1890-1979 was used to accumulate consumption over lifetime for the various birthcohorts according to the method by Todd et al. ${ }^{6}$ In the graphs, lifetime cumulative cigarette consumption in terms of current cigarettes, constant tar cigarettes, or constant nicotine cigarettes was plotted versus the year of birth. The curves join those dying at the same age, but belonging to different birth cohorts. For instance, the curve for men designated by 30 years covers average cumulative consumption per male, smoker or non-smoker, who died aged 25-34 years between 1920 and 1979 and who was born between 1895 and 1945. Any line parallel to the $y$-axis joins cumulative consumption

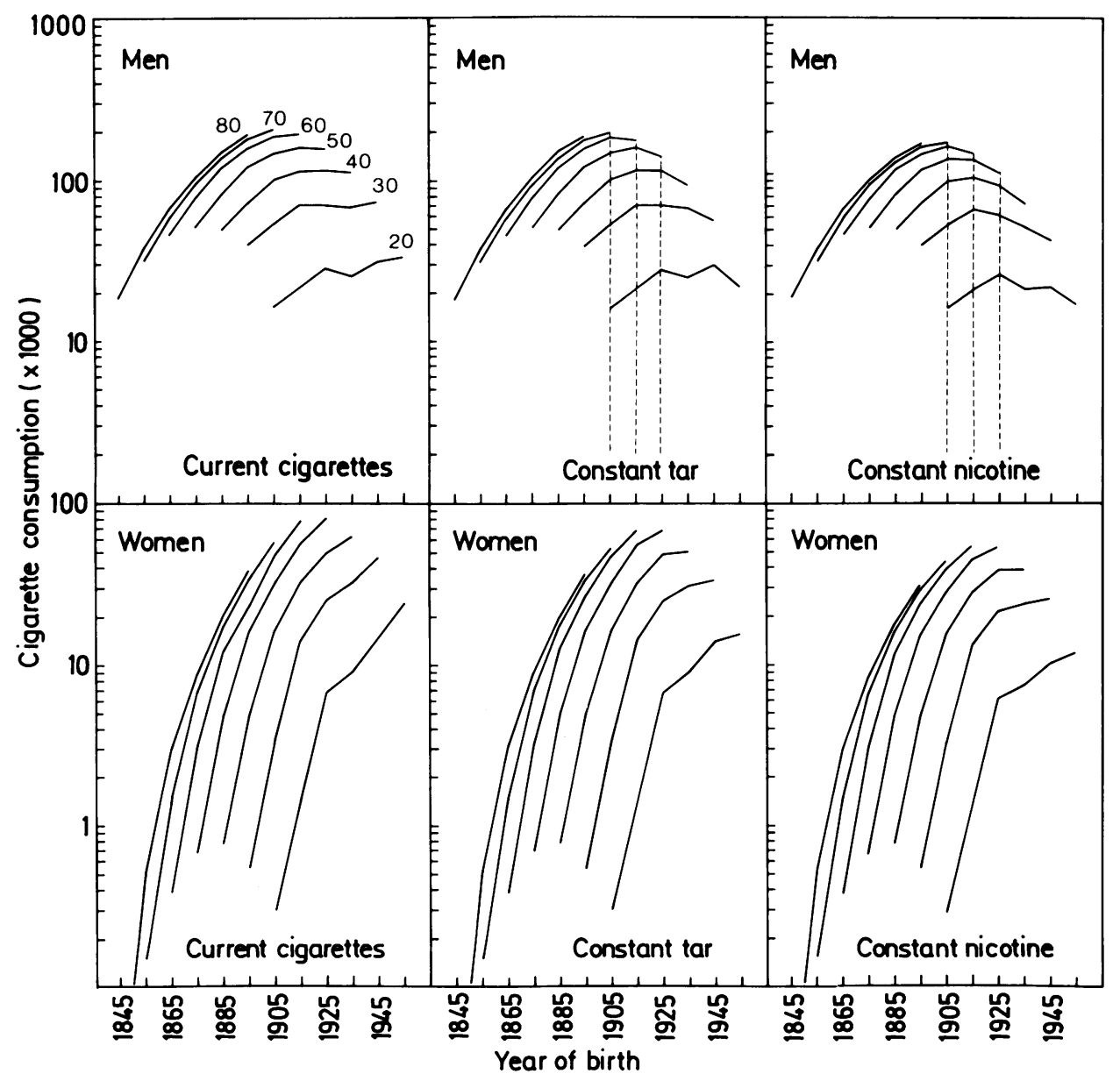

Fig. 2 Cohort age contours of cumulative cigarette consumption in terms of current cigarettes, constant tar cigarettes, and constant nicotine cigarettes, calculation based on tar nicotine deliveries published by Todd. ${ }^{6}$ Each point represents the cumulative consumption over lifetime until the age of death. The curves join persons dying at the same age. 
of persons who were born at the same time, but died at a different age.

The age- and sex-specific numbers of deaths resulting from gastric and duodenal ulcer between 1921 and 1979 were made available by the General Registrars for England and Wales, Scotland, and Northern Ireland. In the calculation of the agespecific death rates, the sum of all the deaths from gastric or duodenal ulcer per 10 year age group and 10 year period was related to the sum of all of living residents in the United Kingdom of the same age and during the same period. For the cohort analysis the age specific death rates were plotted versus the year of birth.

\section{Results}

Figure 1 compares the average number of cigarettes smoked annually per man and woman resident in the UK with the male and female death rates from gastric and duodenal ulcer. The annual number of cigarettes in terms of constant tar or nicotine cigarettes and the death rates from duodenal ulcer seem to run parallel. The peak of male mortality from duodenal ulcer, however, occurs somewhat later than the peak of either tar or nicotine consumption. The decline in female death rates from gastric ulcer runs contrary to the association between gastric ulcer and smoking which might be suggested by looking at the male data only.

The cumulative cigarette consumption based on current cigarettes increased in all male cohorts born between 1845 and 1915 and remained constant for all subsequent birth cohorts (Fig 2). Cumulative cigarette consumption based on constant tar or constant nicotine cigarettes shows a smooth peak for men born in the first quarter of the 20th century. Changes in the estimates of tar and nicotine deliveries of cigarettes according to the data of Wald et al leave the results of the cohort analysis unaffected. In women, cumulative cigarette consumption in terms of current cigarettes increased for all cohorts born between 1835 and 1955 (Fig 2). If cumulative consumption is based on tar or nicotine delivery per cigarette, a plateau of cigarette consumption appears to emerge for those born after 1925 .

For both men and women mortality from gastric ulcer was highest in the cohorts born around 1875 . The highest risk of dying from duodenal ulcer affected male and female cohorts born around 1885 alike, although the subsequent decline was less marked in women than in men (Fig 3).

\section{Discussion}

Much evidence has been accumulated that smoking

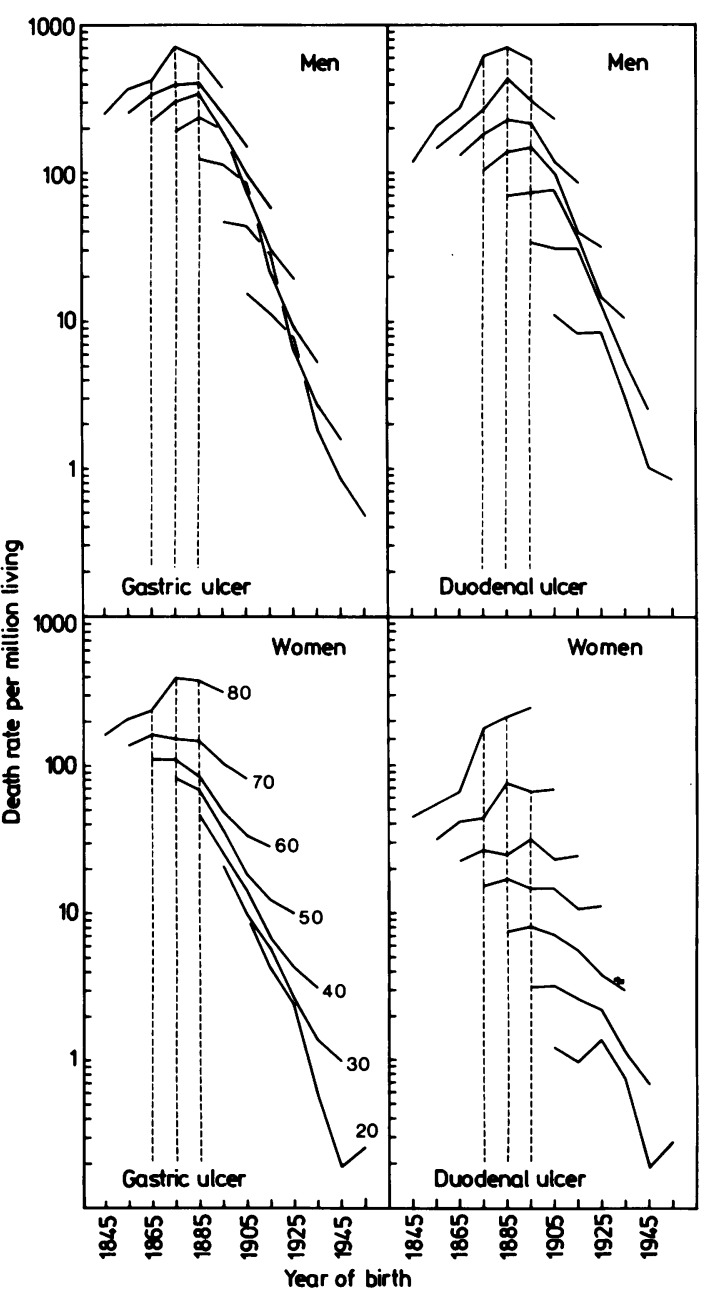

Fig. 3 Cohort age contours of gastric and duodenal ulcer mortality. Each point represents the average death rate of a 10 year period. The curves join person dying at the same age.

and both gastric and duodenal ulcer are strongly associated. ${ }^{10}$ Incidence of peptic ulcer is higher in smokers than in non-smokers. ${ }^{10}$ Cigarette smoking retards ulcer healing and promotes ulcer relapse. ${ }^{11} 12$ Cigarette smoking is a habit common all over the world and taken up at a rather early age. The higher frequency in men fits well with the epidemiology of peptic ulcer.

As most mortality from peptic ulcer occurs during the first year or two after diagnosis, ${ }^{13}$ its trends mainly reflect changes in the incidence. This contention is supported by the fact that patterns compat- 
ible with a birth cohort phenomenon are also found in other parameters of ulcer morbidity. ${ }^{414}$ In addition to incidence, changes in diagnostic and therapeutic practices which were unrelated to smoking could have influenced the death rates. No major changes in coding of mortality occurred until 1950 and 1968 when two separate rubrics for 'gastrojejunal ulcer' and 'peptic ulcer - site unspecified' were added the 6th and 8th revision of the International Classification of Deaths. These two entries were disregarded in the present analysis. They accounted for $1.5 \%$ and $20.5 \%$ of the gastric ulcers during 1970-79. Their overall effect on the cohort pattern for Figure 3 was negligible.

Cigarette smoking did not start in men and women before 1888 and 1920 , respectively. The increase in cigarette consumption occurred at the same time as and seemingly parallel with a marked increase in the mortality of duodenal ulcer (Fig 1). The more differentiated graphs of age-specific death rates and age-specific cumulative cigarette consumption, however, disprove the contention of smoking being the main factor responsible for the pattern of ulcer mortality during the last 60 years. In all age groups, both gastric and duodenal ulcer were already quite frequent before the beginning of cigarette smoking. The death rates of gastric and duodenal ulcer show a similar pattern in men and women. Male and female cohorts with the highest risk of dying from peptic ulcer were born about the same time. Cumulative cigarette consumption is considerably different in men and in women. A peak of cumulative cigarette consumption based on constant tar or nicotine content occurs only in the male cohorts born around 1915, but not in the female birth cohorts. The male cohorts with a high risk of dying from duodenal ulcer were born 30 years earlier than those cohorts with the highest rates of cigarette smoking and uptake of tar or nicotine. The peak of the cohort age contours, if any, is much broader for the cumulative cigarette consumption than for the death rates. The age specific mortality of cohorts born after 1895 already showed a decline when the cumulative cigarette consumption was still on the rise. The lack of correlation between the cohort age contours of cigarette smoking and peptic ulcer mortality suggests that smoking is not the main determinant of the birth cohort phenomenon of peptic ulcer mortality
The author thanks Peter N Lee for his help in the calculation of the cumulative cigarette consumption and Gisela Henze of the Verband der Cigarettenindustrie in Hamburg for her help in assembling the data. The study was supported by the grant no. So 172/1-1 from the Deutsche Forschungsgemeinschaft.

\section{References}

1 Susser M, Stein Z. Civilization and peptic ulcer. Lancet 1962; 1: 115-19.

2 Sonnenberg A, Müller H, Pace F. Birth-cohort analysis of peptic ulcer mortality in Europe. J Chron Dis 1985; 38: $309-17$.

3 Sonnenberg A, Müller H. Cohort and period effects in peptic ulcer mortality from Japan. J Chron Dis 1984; 37: 699-704.

4 Sonnenberg A. Geographic and temporal variations in the occurrence of peptic ulcer disease. Scand J Gastroenterol 1985; 20: suppl 110: 11-24.

5 Todd GF. Changes in smoking patterns in the UK. Occasional paper 1. London: Tobacco Research Council, 1975.

6 Todd GF, Lee PN, Wilson MJ. Cohort analysis of cigarette smoking and of mortality from four associated diseases. Occasional paper 3. London: Tobacco Research Council, 1976.

7 Office of Population Censuses and Surveys. OPCS monitor, general household survey 83/3 - Cigarette smoking: 1972 to 1982. London: Government Statistical Service, 1983.

8 Merzdorf J, Reuter U, Welsch G. Daten und Fakten zur Entwicklung des Rauchens in Mitgliedländern der Europäischen Gemeinschaften. EUR 7907 DE. Luxembourg: Kommission der Europäischen Gemeinschaften, 1982.

9 Wald N, Doll R, Copeland G. Trends in tar, nicotine, and carbon monoxide yields of UK cigarettes manufactured since 1934. Br Med J 1981; 282: 763-765.

10 Harrison AR, Elashoff JD, Grossman MI. Smoking and health. A report of the Surgeon General. DHEW Publ no 79-50066. US Department of Health, Education and Welfare 1979; 9.3-9.21.

11 Sonnenberg A, Müller-Lissner SA, Vogel E, et al. Predictors of duodenal ulcer healing and relapse. Gastroenterology 1981; 81: 1061-7.

12 Sontag S, Graham DY, Belsito A, et al. Cimetidine, cigarette smoking, and recurrence of duodenal ulcer. $N$ Engl J Med 1984; 311: 689-93.

13 Bonnevie O. Survival in peptic ulcer. Gastroenterology 1978; 75: 1055-60.

14 Sonnenberg A. Disability pensions due to peptic ulcer in Germany between 1953 and 1983. Am J Epidemiol 1985; 122: 106-111. 
to learn that the precise mechanism of bilirubin, encephalopathy remains unknown and no technique can be recommended which provides a reliable predictive index of the risk of bilirubin encephalopathy in the individual infant. All chapters critically review the current state of knowledge and define a perspective for further studies. The book will be an essential companion for those interested in bilirubin metabolism. For paediatricians it provides a comprehensive review on all aspects of kernicterus and its prevention, while for the internist the chapters on genetic disorders will be of particular interest.

As is perhaps invariable with a multiple author book, the majority of references date from 1983 , or earlier though in some chapters references up to 1985 have been added in proof. In spite of this criticism this book should be available in all libraries used by gastroenterologists and paediatricians.

ALEX P MOWAT

\section{News}

\section{BSG Research Award 1987}

A three page summary of personal research work is invited by The British Society of Gastroenterology for the 1987 Research Medal. A bibliography may also be submitted if desired. The Award consists of a medal and 1100 prize. The recipient of the Award will be aged 40 years or less when delivering the lecture during the Autumn Meeting of the Society in September 1987. All (or a substantial part) of the work must have been performed in the UK or Eire. Applications (six copies) should be made to: The Honorary Secretary, BSG, 3 St. Andrew's Place, London NW1 4LB, by 1 May 1987.

\section{First ESPEN Scientific Symposium}

This symposium covering current perspectives in nutrition and infection will be held from 13-17 March, 1987 in Jerusalem, Isreal. Further details from Dr HR Freund, Symposium Chairman, PO Box 983, Jerusalem 91009, Israel.

\section{Clinical Controversies in Inflammatory Bowel Diseases}

A symposium on the above will be held from 9-11 September, 1987 at the Palazzo della Cultura, Bologna, Italy. Further information from Mrs Claudia Servisi, SO.GE.PA.CO. Spa, piazza Costituzione, 5/c-40128, Bologna, Italy.

\section{European Association for Gastroenterology and Endoscopy}

The 19th congress of EAGE is to be held from 18-20 June, 1987 in Milan, Italy. Details from Hospital 'L Sacco', Gastrointestinal Unit, Via GB Grassi, 74-20157-Milan, Italy.
Vth International Workshop on Operative Digestive Endoscopy

This workshop will be held from 15-18 June 1987 at the Erasme Hospital, ULB, Brussels, Belgium. Further details from Dr Nadine Bourgeois, Erasme Hospital, 808, Route de Lennik, B-1(170) Brussels, Belgium.

Sixth International Symposium on Viral Hepatitis and Liver Disease

This symposium will be held from 26-28 May 1987 at the Barbican Centre in London. Details from Dr Ralph Kohn, Advisory Service Medical Symposium Ltd, 79 Wimpole St, London W1M 7DD.

XIIth International Update on Liver Disease

To be held from 9-11 July 1987 at the Royal Free Hospital, London. Details from Professor Neil McIntyre, Academic Department of Medicine, Royal Free Hospital, Pond St, London NW3 2QG. Tel: 01-794-(0500, ext. 3969

\section{Computers in Gastroenterology}

This first UK meeting will be held on 12 and 13 May 1987 at the Academic Centre, Whittington Hospital, London. Details from Dr FR Vicary, Whittington Hospital, Highgate Hill, London N19.

\section{Correction}

Re Sonnenberg, Gut, 1986; 27: 1369-72. An error occurred in Figure 1 of this paper and the correct version is printed below.
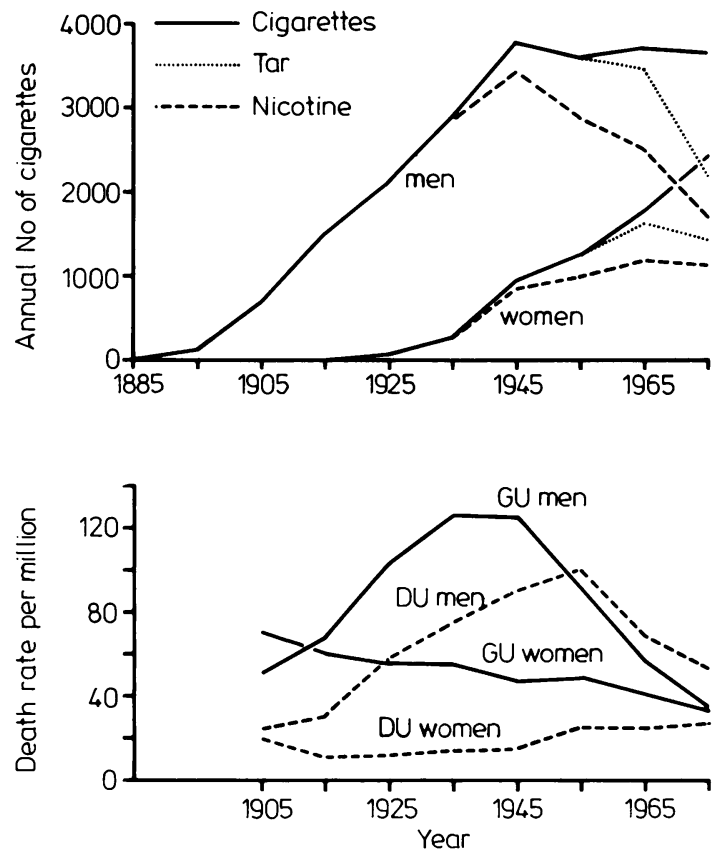